Bond University

Research Repository

\title{
Resilience in Non-Offending Mothers of Children Who Have Reported Experiencing Sexual Abuse
}

McGillivray, Cher J; Pidgeon, Aileen M; Ronken, Carol; Credland-Ballantyne, Catherine A

Published in:

Journal of Child Sexual Abuse

DOI:

10.1080/10538712.2018.1477221

Licence:

Other

Link to output in Bond University research repository.

Recommended citation(APA):

McGillivray, C. J., Pidgeon, A. M., Ronken, C., \& Credland-Ballantyne, C. A. (2018). Resilience in Non-Offending Mothers of Children Who Have Reported Experiencing Sexual Abuse. Journal of Child Sexual Abuse, 27(7), 793-810. https://doi.org/10.1080/10538712.2018.1477221

\section{General rights}

Copyright and moral rights for the publications made accessible in the public portal are retained by the authors and/or other copyright owners and it is a condition of accessing publications that users recognise and abide by the legal requirements associated with these rights.

For more information, or if you believe that this document breaches copyright, please contact the Bond University research repository coordinator 


\section{Resilience in Non-Offending Mothers of Children Who Have Reported Experiencing Sexual Abuse}

\section{Cher J. McGillivray, Aileen M. Pidgeon, Carol Ronken \& Catherine A. Credland-Ballantyne}

To cite this article: Cher J. McGillivray, Aileen M. Pidgeon, Carol Ronken \& Catherine A. Credland-Ballantyne (2018): Resilience in Non-Offending Mothers of Children Who Have Reported Experiencing Sexual Abuse, Journal of Child Sexual Abuse, DOI: 10.1080/10538712.2018.1477221

To link to this article: https://doi.org/10.1080/10538712.2018.1477221

册Published online: 13 Jun 2018.

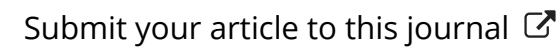

Q View related articles $₫$

View Crossmark data \lceil 


\title{
Resilience in Non-Offending Mothers of Children Who Have Reported Experiencing Sexual Abuse
}

\author{
Cher J. McGillivraya , Aileen M. Pidgeon ${ }^{a}$, Carol Ronken $\mathbb{1}^{\mathrm{b}}$, \\ and Catherine A. Credland-Ballantyne ${ }^{a}$ \\ aFaculty of Society and Design, Bond University, Robina, Queensland, Australia; ${ }^{\circ}$ Bravehearts \\ Foundation, Arundel, Queensland, Australia
}

\begin{abstract}
Growing evidence shows that non-offending mothers experience significant loss and trauma following their child reporting experiencing sexual abuse. Maternal support offered to sexually abused children following disclosure can be a crucial factor in children's recovery. Although mothers are often seen as playing a central role in facilitating the recovery of their sexually abused child, there has been little focus on their own needs and profiles. This present study aimed to increase our understanding of the diversity of profiles of non-offending mothers of sexually abused children by exploring the differences in psychosocial traits of non-offending mothers ( $N=68$; age range 28-67 years) reporting higher and lower resilience.

The mediating role of these psychosocial factors on the relationship between resilience and psychological distress will also be explored. Results found that non-offending mothers in the higher resilience group reported higher levels of positive reappraisal, selfcompassion, social support, and significantly lower levels of psychological distress compared to non-offending mothers in the lower resilience group. Additionally, multiple mediation analysis indicated positive reappraisal, self-compassion, and social support to be significant mediators of the relationship between resilience and psychological distress. Increased levels of self-compassion and social support were found to be predictive of lowered psychological distress, while increased positive reappraisal predicted increased psychological distress. The findings of the present study provide support for the targeting of the psychosocial factors such as self-compassion, social support, and positive reappraisal in interventions for non-offending mothers in an effort to promote resilience.
\end{abstract}

\section{ARTICLE HISTORY}

Received 2 October 2017

Revised 17 February 2018

Accepted 5 May 2018

\section{KEYWORDS}

Child sexual abuse; resilience; positive reappraisal; self-compassion; social support; psychological distress

\section{Introduction}

Child sexual abuse is a pervasive global health problem associated with a number of serious physical and psychological consequences that may impact victims and their families throughout their lives (Clevenger, 2016). Child sexual abuse is

CONTACT Cher J. McGillivray $\triangle$ cmcgilli@bond.edu.au $\Theta$ Bond University, 14 University Drive Robina QLD 4226, Australia.

Color versions of one or more of the figures in the article can be found online at www.tandfonline.com/wcsa. 
defined as any sexual activity perpetrated against a minor by force, threat, intimidation, or manipulation by either an adult or another child or young person. Research indicates one in five children will experience some form of sexual harm prior to reaching 18 years of age (Collin-Vézina, Daigneault, \& Hébert, 2013). Although perpetrators of child sexual abuse can be male or female, the Australian Bureau of Statistics (2006) reported over half of female victims (51.6\%) and one fifth of male victims $(21.4 \%)$ were interfamilial and perpetrated by the father, stepfather, or male relative. The most likely recipient to receive a disclosure from children experiencing sexual abuse, compared with other family and non-family members, are non-offending mothers (Allnock \& Miller, 2013).

Non-offending mothers can be the main source of support while also dealing with their own feelings about the sexual abuse. Many mental health symptoms have been observed in non-offending mothers following their child's disclosure of sexual abuse, including clinically elevated levels of psychological distress, intrusive thoughts, somatization, posttraumatic stress disorder (Dyb, Holen, Steinberg, Rodriguez, \& Pynoos, 2003), and suicidality (Deblinger, Stauffer, \& Landsberg, 1994). Research has noted the impact of a non-offending caregiver's own immediate and long-term psychological distress on potentially diminishing their support toward their child (Regehr, 1990; Tourigny, Hébert, Daigneault, \& Simoneau, 2005).

Parents are reported to experience relational, financial, legal, and residential difficulties contributing to the deleterious outcomes associated with child sexual abuse (Dyb et al., 2003). Additionally, disclosure of sexual abuse to mothers can result in mothers having their children removed from their care for a period of time (Hunter, Coulter, Runyan, \& Everson, 1990), suffering the loss of their relationship with their partner, residence, employment, and becoming dependent on welfare (Dyb et al., 2003). The offender may continue to have access to the child which increases the psychological distress for the protective parent (Hooper, 1992). There is also often an incongruence in the views between parents, professionals, courts, and criminal justice responses, such as the police, as to the best interests of the child (Higgins, 2007).

The strength and supportiveness of the relationship between the nonoffending mother and her child who has experienced sexual abuse has been observed by many researchers as an important element in the healing of the child's recovery from the abuse. The ability of the nonoffending mother to provide and sustain a 'normative' and supportive relationship in the midst of the severe emotional and psychological impacts experienced upon learning a child has been sexually abused, requires resilience (Reitsema \& Grietens, 2016). The current study examined resilience, defined as an individual's capacity to adapt to stress and difficult life events (Thomas \& Otis, 2010), by examining differences in key psychosocial resources between non-offending mothers who report higher and lower levels of resilience. Several key psychosocial resources 
proposed to vary as a function of resilience that are generally agreed upon in the research include positive reappraisal (Green, Coupe, Fernandez, \& Stevens, 1995), self-compassion (Leary et al., 2007), and social support (Tedeschi \& Calhoun, 2004).

Current literature on the effects of child sexual abuse upon the parents has emerged from studies that have focused on negative psychological outcomes. There is a lack of focus in understanding how parents go on to experience positive psychological outcomes (Tedeshi \& Calhoun, 2004). Although resilient individuals have been shown to experience lowered psychological distress (Fredrickson, Tugade, Waugh, \& Larkin, 2003) there is a significant gap in the literature in understanding the experiences of non-offending mothers in an abuse-reporting situation as well as understanding how to support them. Resilience is considered critical to extend the knowledge base around psychological characteristics, as it contributes to adaptive responding that ultimately benefits both the non-offending mother and the child (Reitsema \& Grietens, 2016).

One of the first theories to explore the relationship between adversity and resilience was Fredrickson's (1998) broaden-and-build theory. Fredrickson (1998) proposed that positive emotions broaden a person's attentional focus and promote the building of personal resources. Research suggests that positive emotions build resources such as positive reappraisal, self-compassion, and social support which are related to reduced psychological distress (Fredrickson, Cohn, Coffey, Pek, \& Finkel, 2008). Folkman and Moskowitz (2000) suggested that positive reappraisal is a coping strategy that may protect against stress, maintain resilience, and reduce psychological distress. Self-compassion has been shown to contribute to resilience and increased social connectedness (Wei, Liao, Ku, \& Shaffer, 2011).

In the current study, the broaden-and-build theory was applied to propose that the experience of resilience promotes the broadening of psychological resources such as self-compassion and positive reappraisal, and the building of personal resources such as social support (Garland, Gaylord, \& Fredrickson, 2011; Tedeschi \& Calhoun, 2004). Such adaptive outcomes stemming from a protective characteristic could diminish psychological distress in non-offending mothers following their child experiencing sexual abuse. Further, theoretical predictions imply an increase in adaptive outcomes could also strengthen the non-offending mother's resilience levels, prompting additional adaption in an ever-increasing upward spiral.

Furthermore, resilience has been recognized as a framework to examine the differences between individuals who either thrive or struggle to cope (Keye \& Pidgeon, 2013; Pidgeon, Rowe, Stapleton, Magyar, \& Lo, 2014; Swanson, Valiente, Lemery-Chalfant, \& O’Brien, 2014). Although previous research has found associations between higher levels of resilience, positive reappraisal, self-compassion, and social support, and lower 
psychological distress in general adult populations (Abbott, Klein, Hamilton, \& Rosenthal, 2009), very few have examined these characteristics among non-offending mothers whose children have reported experiencing sexual abuse (Plummer \& Eastin, 2007).

\section{The current study}

To address these research gaps, the present study aimed to add to the body of knowledge on resilience by examining the psychosocial factors of resilient mothers across the characteristic profiles of positive reappraisal, social support, self-compassion, and psychological distress. A multiple mediation analysis was utilized within the broaden-and-build theory which suggests that resilience interacts concurrently with social support, self-compassion, and positive reappraisal, and not in isolation. The presence of these psychosocial factors may carry important implications for resilience-based treatment formulation and the development of prevention strategies. Based on previous studies the following predictions were tested.

Hypothesis 1: It was predicted that non-offending mothers who reported higher levels of resilience would report significantly higher levels of positive appraisal, self-compassion, social support, and lower levels of psychological distress compared to non-offending mothers reporting lower levels of resilience.

Hypothesis 2: It was predicted that positive reappraisal, self-compassion, and social support would all uniquely, significantly mediate the relationship between resilience and psychological distress.

\section{Methods}

\section{Participants}

Participants consisted of 68 non-offending mothers aged between 28 and 67 years of age $(M=43.22, S D=8.12)$ of at least one child who had experienced sexual abuse. Some of the sample reported multiple categories of abuse. Of this sample overlapping reports of abuse by a family member (77.9\%) included the type of abuse reported as sexual (72.1\%), emotional (32.4\%), mental (29.4\%), and physical (29.4\%). The remaining sample comprised of participants whose children reported abuse by a non-family member $(25 \%)$ sexual (22.1\%), emotional (7.4\%) mental (7.4\%), and physical (7.4\%). Psychological maltreatment is defined as an adult's destructive rejection, isolation, corrupting, ignoring or terrorizing of a child (Garbarino, 
Guttman, \& Seeley, 1986). Emotional abuse, although often related is not considered synonymous the adverse effect on the child's emotional and behavioral development from enduring rejection or emotional hostile behavior (Department of Health, United Kingdom, 1991).

Scores on the Depression Anxiety and Stress Scales-21 (DASS-21) indicating parent well-being for anxiety ranged from normal (20.4\%), mild (19.1\%), severe (7.4\%), and extremely severe (35.3\%). Stress ranged from normal (36.8\%), mild (17.6\%), moderate (19.1\%), severe (13.2), and extremely severe (13.2\%). Clients indicating depression symptoms ranged from normal (36.8\%), mild (17.6\%), moderate (19.1\%), severe (13.2\%), and extremely severe (13.25). These figures are above the prevalence figures in the standard Australian population (14.4\% for anxiety disorders, and $6.2 \%$ for affective disorders, based on data from the Australian National Survey on Mental Health and Wellbeing, 2007).

\section{Procedure}

Ethics approval was granted and a non-probability, convenience-sampling method was used to recruit participants within a specialist child sexual abuse organization. Participants were directed to the survey-hosting website PsychData to administer the assessments.

\section{Measures}

\section{Psychological distress}

Psychological distress in mothers was measured by the Depression Anxiety and Stress Scales-21 (DASS-21; Lovibond \& Lovibond, 1995). The DASS-21 is a 21item self-report measure relating to three factors of psychological distress: depression, anxiety, and stress. The scale demonstrates strong internal consistency with a Cronbach's alpha of $\alpha=.91$ (Lovibond \& Lovibond, 1995). Responses are made on a 4-point Likert scale ranging from $0=$ did not apply to me at all to $3=$ applied to me very much, or most of the time with higher scores indicating greater severity of psychological distress symptomology. Example items include "I found it hard to wind down" and "I felt that I had nothing to look forward to". Convergent, construct and discriminant validity of the DASS21 have been well established (Lovibond \& Lovibond, 1995). A reliability analysis of the scale in the current study's sample demonstrated a comparable level of internal consistency with Cronbach's alpha of $\alpha=.97$. 


\section{Resilience}

Resilience was assessed using the Connor-Davidson Resilience Scale (CD-RISC; Connor \& Davidson, 2003). The CD-RISC has shown to exhibit acceptable levels of reliability and validity (Connor \& Davidson, 2003). The CD-RISC consists of 25-statements the participant must rate in applicability to themselves. Participants rate each statement in terms of how they have felt over the past month using a 5-point Likert scale ranging from $0=$ not true at all to $4=$ true nearly all the time. Sample items include "Having to cope with stress can make me stronger" and "Good or bad, I believe most things happen for a reason." The CD-RISC has demonstrated good reliability with Cronbach's alpha $\alpha=.88$ and .89 , and well established convergent and divergent validity in the development of the scale (Connor \& Davidson, 2003). Overall the current study showed moderate internal consistency with Cronbach's alpha $\alpha=.94$.

\section{Positive reappraisal}

The Cognitive Emotional Regulation Questionnaire (Cordova, Cunningham, Carlson, \& Andrykowski, 2001) was used to identify positive reappraisal. The current study specifically utilized the four-item CERQ Positive Reappraisal subscale. The items describe general thinking patterns that commonly occur when experiencing a negative events and are rated on a 5-point Likert-scale that range from 1 = almost never to $5=$ almost always. Sample items from this subscale include "I think I can learn something from the situation" and "I think that I can become a stronger person as a result of what has happened". The CERQ has sound internal consistency (Garnefski, Kraaij, \& Spinhoven, 2001) and demonstrated moderate internal consistency of the positive reappraisal subscale of the CERQ with Cronbach's alpha of $\alpha=.79$ in the sample analyzed. Convergent and discriminant validity have been well established (Hoekstra, Ormel, \& De Fruyt, 1996).

\section{Self-compassion}

The Self-Compassion Scale (SCS; Neff, 2003) is a 26-item self-report measure used to measure the emotional construct of self-compassion. Participants are instructed to rate each item using a 5-point Likert-scale. Responses range from 1 = almost never to 5 = almost always. Example items include "I'm kind to myself when I'm experiencing suffering" and "I try to be loving towards myself when I'm feeling emotional pain.” The SCS has demonstrated strong internal reliability for its subscales $(\alpha=.77$ to $\alpha=.80)$ and total scale $(\alpha=.92)$ across a range of samples and has well established discriminant, 
construct and convergent validity (Neff, 2003). A reliability analysis of the scale in the present study shows moderate internal consistency with Cronbach's alpha of $\alpha=.94$.

\section{Social support}

Social support was assessed using the Social Provisions Scale (SPS; Cutrona \& Russell, 1987). The scale has 24 items in which participants rated their agreement with each item using a 5-point Likert scale ranging from $1=$ strongly disagree to $4=$ strongly agree. Sample items include "There are people I know will help me if I really need it" and "I have close relationships that make me feel good". The SPS is a measure that was designed to assess six provisions of social relationships. Reliability for the SPS ranges from .87 to .91 across a range of samples (Cutrona \& Russell, 1987).

\section{Statistical analysis}

To examine group differences, a one-way between groups MANOVA design was employed with resilience as the independent variable (IV) as measured by the CD-RISC. Resilience was divided using a median split to categorize participants that were higher $(N=34,50 \%)$ and lower in resilience $(N=34$, 50\%). Hirt et al. (2004) indicated that median splits have been considered a respected analytic technique. Iacobucci et al. (2015) has also shown the acceptability of median splits as they do not increase the likelihood of Type 1 errors and are beneficial when independent variables are not correlated.

The four continuous dependent variables (DVs) were psychological distress, positive reappraisal, self-compassion, and social support. To assess predictive relationships between the variables, a multiple mediation analysis was conducted, using resilience as the predictor variable and psychological distress as the criterion.

\section{Results}

\section{Preliminary analyses}

A number of descriptive statistics were first carried out. The assumption of normality was met through an inspection of histograms and showed appropriate distribution. The values of skewness and kurtosis were not exceeding values of -3 and +3 (Tabachnick \& Fidell, 2013). Linearity was assessed using scatterplots and revealed a linear relationship between the variables. Results are presented below in Table 1 with a summary of intercorrelations and descriptive statistics on all variables. 
Table 1. Summary of intercorrelations, uncentered means, and standard deviations for psychological distress, resilience, positive reappraisal, self-compassion, and social support $(N=68)$.

\begin{tabular}{llllcccr}
\hline Variable & 1 & 2 & 3 & 4 & 5 & $M$ & \multicolumn{1}{c}{$S D$} \\
\hline 1. Psychological Distress & - & & & & & 49.47 & 32.17 \\
2. Resilience & $.45^{* *}$ & - & & & & 63.54 & 16.51 \\
3. Positive Reappraisal & -.09 & $.59^{* *}$ & - & & & 10.44 & 3.88 \\
4. Self-Compassion & $-.62^{* *}$ & $.62^{* *}$ & $.46^{* *}$ & - & & 75.34 & 19.30 \\
5. Social Support & $-.40^{* *}$ & $.61^{* *}$ & $.46^{* *}$ & $-.40^{* *}$ & - & 75.90 & 11.52 \\
\hline
\end{tabular}

Note. ${ }^{*} p<.05 .{ }^{* *} p<.001$

As predicted, a range of moderate to large significant correlations was observed between the majority of key variables. Although not hypothesized, a non-significant inverse relationship was found between psychological distress and positive reappraisal.

\section{MANOVA}

A one-way between groups MANOVA tested the hypothesis that psychological distress, positive reappraisal, self-compassion, and social support would significantly differ between mothers who reported higher levels of resilience in comparison to mothers who reported lower levels of resilience. Multivariate analyses showed that there was a significant influence of resilience on the combined variables, $F(4,63)=17.10, p<.001, \eta_{\mathrm{p}}^{2}=.52$, power $\leq 1.00$. The results also suggested the combined dependent variables accounted $52 \%$ of the variance between the higher and lower resilience.

To follow up the significant multivariate result, univariate ANOVAs were run. Results demonstrated a significant difference between resilience groups for psychological distress, $F(1,66)=11.10, p=.001, \eta_{\mathrm{p}}^{2}=.14$, power $=.91$; positive reappraisal $F(1,66)=33.52, p<.001, \eta_{\mathrm{p}}^{2}=.34$, power $=>1.00$; self-compassion $F$ $(1,66)=24.62, p<.001, \eta_{\mathrm{p}}^{2}=.27$, power $=>.99$; and social support $F(1$, 66) $=34.85, p<.001, \eta_{\mathrm{p}}^{2}=.13$, power $=>1.00$. Table 2 displays the means and standard deviations for the dependent variables between resilience groups. The higher resilience group reported significantly lower levels of psychological distress than the lower resilience group. Furthermore, the higher resilience group reported significantly higher levels of positive reappraisal, self-compassion and social support compared to the lower resilience group.

Table 2. Means and standard deviations between resilience groups (higher versus lower), psychological distress, positive reappraisal, self-compassion, and social support $(N=68)$.

\begin{tabular}{lll}
\hline Variable Higher Resilience (34) Lower Resilience (34) & \multicolumn{1}{c}{$M(S D)$} & $M(S D)$ \\
\hline Psychological Distress & $37.35(31.97)$ & $61.59(27.87)$ \\
Positive Reappraisal & $12.68(3.54)$ & $8.21(2.78)$ \\
Self-compassion & $85.32(17.29)$ & $65.35(15.87)$ \\
Social Support & $82.62(8.60)$ & $69.18(10.12)$ \\
\hline
\end{tabular}


a) Unmediated Model

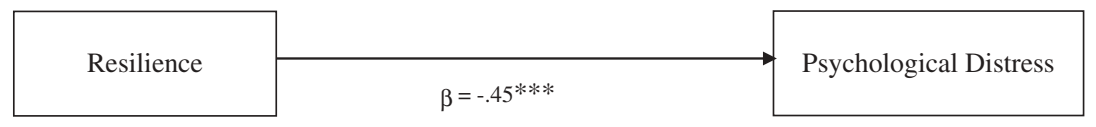

b) Mediated Model

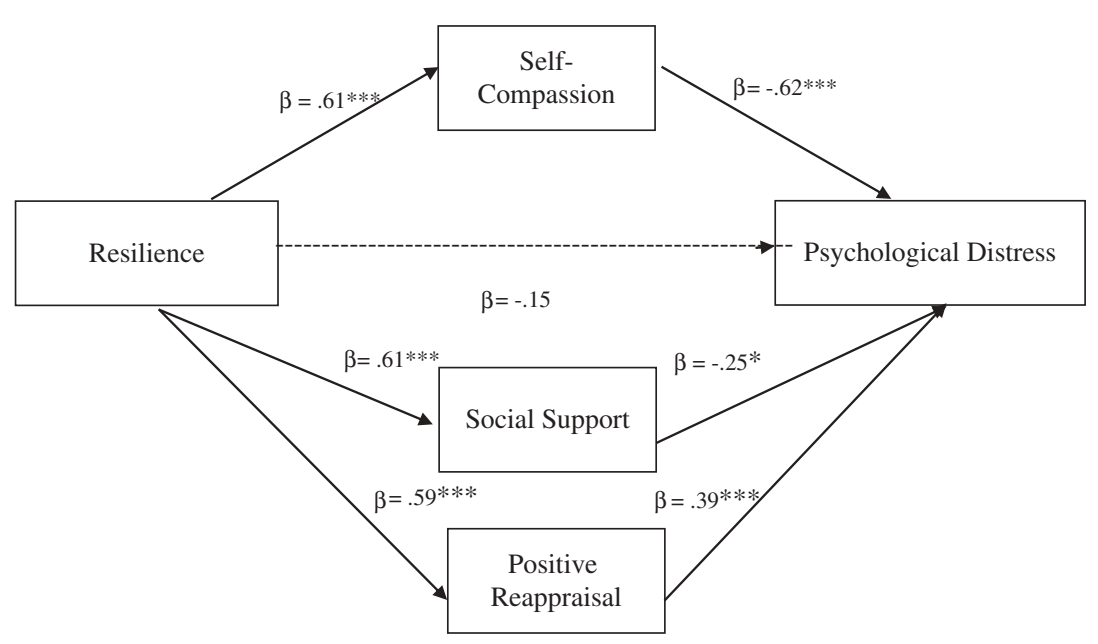

Figure 1. Multiple mediation of the relationship between resilience and psychological distress. Unmediated model (a) and mediated model (b). Note. ${ }^{*} p<.05 p<.01^{* *} p<.001{ }^{* * *}$

\section{Multiple mediation analysis}

In order to test the hypothesis that self-compassion, social support, and positive reappraisal would mediate the relationship between resilience and psychological distress, a multiple mediation analysis was conducted. The analysis was conducted utilizing 1000 bootstrapped samples.

Figure 1 contains a graphical summary of the mediation analysis including standardized values and significance levels. The unmediated total effect (Path C) was found to be significant, such that resilience was a significant negative predictor of psychological distress. Further, all three mediators displayed significant, predictive relationships with resilience, demonstrative of Path A.

Further to this, all mediators were found to demonstrate significant relationships with the criterion variable of psychological distress. This is illustrative of Path B, and in combination with the established Path As, all mediators form a complete indirect effect. Self-compassion and social support were significant negative predictors of psychological distress. Specifically, an increase in either self-compassion or social support independently was predictive of a decrease in psychological distress reports. Higher levels of self-compassion predicted lower psychological distress. 
Unexpectedly, positive reappraisal was a significant positive predictor of psychological distress. An increase in positive reappraisal tendencies predicted an increase in psychological distress severity. When all mediator variables were considered, the direct effect of resilience predicting psychological distress (Path $\mathrm{C}^{\prime}$ ) was found to be non-significant, demonstrating a substantial reduction in its standardized coefficient from the original unmediated relationship.

Significant mediation effects were observed for all variables of self-compassion ( $95 \% \mathrm{CI}=-.60$ to $95 \% \mathrm{CI}=-.22$ ), social support $(95 \% \mathrm{CI}=-.31$ to $95 \% \mathrm{CI}=-.03)$, and positive reappraisal $(95 \% \mathrm{CI}=.11$ to upper $95 \%$ $\mathrm{CI}=.38)$. The total mediation variable $(95 \% \mathrm{CI}=-.56$ to $95 \% \mathrm{CI}=-.07)$ was reflective of the indirect effect comprised of a combination of the mediators, which also demonstrated significance.

Pairwise contrasts found a significant difference in the strength of positive reappraisal and self-compassion as mediators to the relationship between resilience and psychological distress $(95 \% \mathrm{CI}=.40$ to $95 \% \mathrm{CI}=.87)$. Selfcompassion $\left(\beta_{\mathrm{ab}}=-.38\right)$ was found to be stronger than positive reappraisal $\left(\beta_{\mathrm{ab}}=.23\right)$. Further, a significant difference was also found between the strength of positive reappraisal and social support as mediators (95\% $\mathrm{CI}=.19$ to $95 \% \mathrm{CI}=.60)$ whereby positive reappraisal $\left(\beta_{\mathrm{ab}}=.23\right)$ was stronger than social support $\left(\beta_{\mathrm{ab}}=-.15\right)$. Overall, the findings indicated that the relationship between resilience and psychological distress was significantly mediated by self-compassion, social support, and positive reappraisal independently and in combination.

\section{Discussion}

The purpose of this study was to examine the characteristics of resilience in non-offending mothers of children who have reported experiencing sexual abuse. The study aimed to assess group differences between non-offending mothers reporting higher and lower resilience. The two groups, higher resilient and lower resilient non-offending mothers, were compared on the variables of psychological distress, positive reappraisal, self-compassion, and social support. Further, the present study examined the mediating role of positive reappraisal, self-compassion, and social support on the combined relationship between resilience and psychological distress.

Overall, the results supported hypothesis one. Consistent with previous research, a significant positive relationship was observed between resilience and positive reappraisal (Folkman \& Moskowitz, 2000), resilience and selfcompassion (Leary, et al., 2007), and resilience and social support (Turner, 1981). As predicted and also consistent with previous research, resilience and psychological distress were found to be significantly negatively correlated, however, there was a non-significant association observed between positive 
reappraisal and psychological distress. The result displayed a similar inverse relationship to that found in previous literature (Affleck \& Tennen, 1996; Rosmond, 2005).

MANOVA analyses found the multivariate main effect of resilience to reveal statistically significant differences between the higher and lower level resilience groups on the combined dependent variables of positive reappraisal, self-compassion, and social support. As predicted, non-offending mothers with higher levels of resilience reported significantly greater levels of positive reappraisal in comparison to non-offending mothers with low levels of resilience. These results are in line with previous research on mothers of children who have experienced trauma, wherein mothers who reported greater resilience also reported experiencing higher levels of positive reappraisal (Gross \& John, 2003). The broaden-and-build theory proposed that positive emotions broaden a person's attentional focus and promote the building of personal resources (Fredrickson, 1998). In accordance with this theory, the observed group differences suggest that resilience may be associated with the building of the psychological resource of positive reappraisal.

Non-offending mothers who reported higher levels of resilience were also found to report significantly greater levels of self-compassion in comparison to mothers with lower levels of resilience. These results offer support for the association Neff et al. (2007) made between higher rates of resilience and subsequent self-compassion. Further, as predicted mothers with higher levels of resilience reported significantly higher levels of social support in comparison to those with lower levels of resilience. Again this is supported by comparative research (Elliott \& Carnes, 2001; Lam \& Grossman, 1997).

Self-compassion was found to be a significant negative predictor of psychological distress with higher levels of self-compassion predicting lower levels of psychological distress in line with previous research (Zeller, Yuval, Nitzan-Assayag, \& Bernstein, 2015). Social support was also found to be a significant negative predictor of psychological distress with greater levels of social support predicting lowered psychological distress. This finding also lends support to Raffaelli et al. (2013) who proposed that social support has shown to play a key role in reducing levels of psychological distress. Positive reappraisal was found to be a significant positive predictor of psychological distress in line with research indicating a bi-directional relationship between psychological distress and resilience (Zoellner \& Maercker, 2006).

Hypothesis two predicted that self-compassion, social support, and positive reappraisal were all significant mediators of the relationship between resilience and psychological distress. Higher resilience was found to predict higher self-compassion and higher social support, both of which in turn uniquely predicted lowered psychological distress. Results indicated that self-compassion mediated the relationship between resilience and psychological distress. Research has similarly demonstrated the 
presence of higher resilience predictive of perceived social support found in survivors of child sexual abuse along with lower psychological distress (Lam \& Grossman, 1997).

However contrary to predictions, greater levels of positive reappraisal were found to uniquely account for increased levels of psychological distress. The results provide partial support to the implied inverse relationship of positive reappraisal and psychological distress found in other trauma populations (Zoellner \& Maercker, 2006). For example, higher levels of active positive reappraisal have been found to be related to higher levels of psychological distress (Silver et al, 1983) in adult survivors of childhood abuse. It has been suggested that positive reappraisal strategies may be used to avoid direct processing of the trauma which initially appear too confronting. In this way, the individual is unable to reduce their psychological distress as they have not addressed the trauma, merely restructured it; in essence, the trauma remains untouched.

Positive reappraisal may also maintain avoidance behaviors which exacerbate psychological distress (Zoellner \& Maercker, 2006). The distressing effects of positive reappraisal may be interpreted as a product of the ongoing stressors and conflicts within the child protection system or criminal justice system (Dyb et al., 2003; Higgins, 2007; Hooper, 1992). Within this system positive reappraisal may be a coping method to keep moving forward where positive outcomes always feel always out of reach.

\section{Limitations}

The utilization of self-report Likert-based measures evaluating positive psychological constructs may have introduced compliance bias. A semantic differential response format may be an alternative for reducing this (Friborg, Martinussen, \& Rosenvinge, 2006). Participants may have rated themselves as more resilient or mindful or suffering from less psychological distress, however a reduction to the threat of social desirability was controlled for by the confidentiality of the participation. Although it may be thought that retrospective self-reports may lead to biases or distortions in recall, critical analysis of retrospective child sexual abuse self-reports have shown not to affect the association between child abuse and later outcomes (Brewin, Andrews, \& Gotlib, 1993).

A further limitation was that the sample size was constrained due to self-selection. Future replication with a greater cohort of parents from different cultural backgrounds, countries, including those who do not have access to support organizations, and non-offending fathers or caregivers would provide further clarity due to the mixed findings in literature, particularly around the role of positive reappraisal in a vulnerable population. A lack of a control group makes it difficult to draw a clear 
conclusion from the study regarding the difference in reported mental health problems between the parents of children with children who have experienced abuse and the parents of children whose children have not experienced abuse (Slade, Johnston, Oakley Browne, Andrews, \& Whiteford, 2009). Therefore greater caution is recommended in interpretation of these findings.

\section{Implications for future research}

The findings of the present study hold important implications for future research and current application of support programs to non-offending mothers of children who have experienced abuse. Future research could extend these findings to examine further relationships among these key psychosocial variables in clinically oriented settings. A subsequent focus for studies could investigate causal relationships between the key study variables, perhaps by temporal manipulation of various interventions. Alternatively, research might investigate the moderating effects of self-compassion and social support programs on resilience-based treatments. In light of the findings of this research and focus on the coping mechanisms of parents, future researchers may benefit from controlling for the severity, duration, timing of the sexual abuse and disclosures, and stage of court involvement. Future researchers may also consider age, gender, impact ofintrafamilial or extrafamilial abuse on the relationship to the study variables.

As previously noted, self-compassion and social support may be the mechanisms through which resilience reduces psychological distress for non-offending mothers whose children have reported experiencing sexual abuse. For example, when mothers possess high resiliency, using self-compassion and social support enables them to process the information in a more adaptive way that is compassionate to themselves therefore promoting meaning and psychological adjustment. Self-compassion based therapies and social support have shown to reduce psychological distress following a range of other traumatic events, and this current study provides findings that selfcompassion and social support both in combination and uniquely facilitate the relationship between resilience and psychological distress for non-offending mothers when related to the sexual abuse of a child.

The findings of this study contribute to the body of literature on resilience within maternal support, and by extension aid parents and children with post-abuse adjustment (Zajac, Ralston, \& Smith, 2015). The findings bolster the broaden-and-build theory of positive emotions and the conceptualization of resilience as a personal resource through its association with positive reappraisal.

The current study is among the first to explore differences in personal characteristics of positive reappraisal, self-compassion, and social support 
between non-offending mothers with higher and lower resilience levels. The findings of this study contribute to further identifying the characteristics of resilient mothers who have the ability to flourish under significant challenges. Resilience may be the key to providing adequate support for their child, resulting in the child receiving greater emotional support from the parent (Yancey \& Hansen, 2010). Exploring the characteristics of nonoffending mothers whose children have been sexually abused can provide insight into the role of personal characteristics which could be utilized in the development of education interventions where governments provide community-based opportunities. Self-compassion and social support based resilience interventions may enhance individuals' ability to access both environmental and personal resources to develop their resilience in meaningful ways (Ungar, 2008).

Protective factors are particularly significant for those with histories of abuse, as the elevated risk functions as an activating factor to resilience (Lam \& Grossman, 1997). Rutter (1987) suggested opportunities continue to exist for organizations and individuals to foster resilience in recovery from child sexual abuse, to focusing on building personal strengths, enhancing positive coping skills, increasing external supports, and generating opportunities for success. Given the centrality of a mothers' supporting role in children's outcomes (Hanson, Saunders, \& Lipovsky, 1992) a focus on facilitating adaptive factors that mothers can use proactively to guard against psychological distress deserves serious consideration.

\section{Notes on contributors}

Cher McGillivray is a PhD Scholar. She has completed a Graduate Diploma of Psychological Science and Masters of Psychology (Clinical) at Bond University where she also works as a tutor. She continues to work in private practice with research interests in trauma recovery and resilience with abused children and their families.

Aileen Pidgeon is a Clinical Psychologist and A/Professor of Psychology at Bond University, Gold Coast. She has co-authored over 30 publications. Her PhD resulted in publishing and disseminating the Pathways Triple P-Positive Parenting Program for at risk families. This program is an internationally recognized program that is currently in use across 25 countries worldwide with 30,000 practitioners having delivered the intervention to many families. Dr. Pidgeon's current research interest the role of mindfulness in cultivating resilience and wellbeing and reducing stress in university students, therapists working with at risk young people, and mothers of children who have experienced trauma. Dr. Pidgeon has developed and is currently evaluating the mindfulness-based program and app called MARST (Mindful Awareness Resilience Skills Training) with these populations.

Carol Ronken worked as a researcher and Associate Lecturer at Griffith University in the School of Criminology and Criminal Justice before joining Bravehearts in early 2003. In 2011, she received an award from the Queensland Police Service Child Protection and Investigation Unit for her contribution to child protection. Carol also co-authored The Bravehearts Toolbox 
for Practitioners Working with Child Sexual Assault (Australian Academic Press, 2011). Carol is also currently a visiting fellow in the School of Justice, Faculty of Law, at Queensland University of Technology.

Catherine Credland-Ballantyne has just completed a Bachelor of Psychological Science (Honours) at Bond University, where she also works as a research assistant. Catherine has an interest in posttraumatic growth and the positive personal attributes that support growth in the aftermath of a traumatic event. She hopes to continue her research via a Masters in Clinical Psychology.

\section{ORCID}

Carol Ronken (10) http://orcid.org/0000-0002-4338-3457

\section{References}

Abbott, J.-A., Klein, B., Hamilton, C., \& Rosenthal, A. J. (2009). The impact of online resilience training for sales managers on wellbeing and performance. E-Journal of Applied Psychology, 5, 89-95. doi:10.7790/ejap.v5i1.145

Affleck, G., \& Tennen, H. (1996). Construing benefits from adversity: Adaptional significance and dispositional underpinnings. Journal of Personality, 64, 899-922. doi:10.1111/j.14676494.1996.tb00948

Allnock, D., \& Miller, P. (2013). No one noticed, no one heard: A study of disclosures of childhood abuse. Retrieved from: http://uobrep.openrepository.com/uobrep/handle/ $10547 / 600875$

Australian Bureau of Statistics. (2006). Personal safety survey, Australia, 2006 (Cat No. 4906.0). Canberra, Australia:Author.

Brewin, C. R., Andrews, B., \& Gotlib, I. H. (1993). Psychopathology and early experience: A reappraisal of retrospective reports. Psychological Bulletin, 113, 82-98. doi:10.1037/00332909.113.1.82

Clevenger, S. (2016). Mothers of sexual assault victims: How women "do mother" after their child has been sexually assaulted. Feminist Criminology, 11, 227-252. doi:10.1177/ 155708511558602410.1177 ? 1557085115586024

Collin-Vézina, D., Daigneault, I., \& Hébert, M. (2013). Lessons learned from child sexual abuse research: Magnitude, aftermath, and prevention strategies. Child and Adolescent Psychiatry and Mental Health, 7, 1-9. doi:10.1186/1753-2000-7-22

Connor, K. M., \& Davidson, J. R. (2003). Development of a new resilience scale: The Connor-Davidson resilience scale (CD-RISC). Depression and Anxiety, 18, 76-82. doi:10.1002/da.10113

Cordova, M. J., Cunningham, L. L., Carlson, C. R., \& Andrykowski, M. A. (2001). Posttraumatic growth following breast cancer: A controlled comparison study. Health Psychology, 20, 176-185. doi:10.1037/0278-6133.20.3.176

Cutrona, C. E., \& Russell, D. W. (1987). The provisions of social relationships and adaptation to stress. Advances in Personal Relationships. 1, 37-67. Retrieved from https://www. researchgate.net/profile/Daniel_Russell4/publication/271507385_The_Provisions_of_ Social_Relationships_and_Adaptation_to_Stress/links/54c960b40cf2807dcc265ce2.pdf 
Deblinger, E., Stauffer, L., \& Landsberg, C. (1994). The impact of a history of child sexualabuse on maternal response to allegations of sexual abuse concerning her child. Journal of Child Sexual Abuse, 3, 67-75. doi:10.1300/J070v03n03_05

Department of Health, United Kingdom. (1991). Working together. London, UK: HMSO.

Dyb, G., Holen, A., Steinberg, A. M., Rodriguez, N., \& Pynoos, R. S. (2003). Alleged sexual abuse at a day care center: Impact on parents. Child Abuse \& Neglect, 27, 939-950. doi:10.1016/S0145-2134(03)00141-8

Elliott, A. N., \& Carnes, C. N. (2001). Reactions of nonoffending parents to the sexual abuse of their child: A review of the literature. Child Maltreatment, 6, 314-331. doi:10.1037/00029432.77.4.534

Folkman, S., \& Moskowitz, J. T. (2000). Positive affect and the other side of coping. American Psychologist, 55, 647-654. doi:10.1037/0003-066X.55.6.647

Fredrickson, B. L. (1998). What good are positive emotions? Review of General Psychology, 2, 300-319. doi:10.1037/1089-2680.2.3.300

Fredrickson, B. L., Cohn, M. A., Coffey, K. A., Pek, J., \& Finkel, S. M. (2008). Open hearts build lives: Positive emotions, induced through loving-kindness meditation, build consequential personal resources. Journal of Personality and Social Psychology, 95, 1045-1062. doi:10.1037/a0013262

Fredrickson, B. L., Tugade, M. M., Waugh, C. E., \& Larkin, G. R. (2003). What good are positive emotions in crisis? A prospective study of resilience and emotions following the terrorist attacks on the United States on September 11th, 2001. Journal of Personality and Social Psychology, 84, 365. doi:10.1037/0022-3514.84.2.365

Friborg, O., Martinussen, M., \& Rosenvinge, J. H. (2006). Likert-based vs. semantic differential-based scorings of positive psychological constructs: A psychometric comparison of two versions of a scale measuring resilience. Personality and Individual Differences, 40, 873-884. doi:10.1016/j.paid.2005.08.015

Garbarino, J., Guttman, E., \& Seeley, J. W. (1986). The psychologically battered child. San Francisco, CA: Jossey Bass.

Garland, E. L., Gaylord, S. A., \& Fredrickson, B. L. (2011). Positive reappraisal mediates the stress-reductive effects of mindfulness: An upward spiral process. Mindfulness, 2, 59-67. doi:10.1007/s12671-011-0043-8

Garnefski, N., Kraaij, V., \& Spinhoven, P. (2001). Negative life events, cognitive emotion regulation and emotional problems. Personality and Individual Differences, 30, 1311-1327. doi:10.1016/S0191-8869(00)00113-6

Green, A. H., Coupe, P., Fernandez, R., \& Stevens, B. (1995). Incest revisited: Delayed posttraumatic stress disorder in mothers following the sexual abuse of their children. Child Abuse \& Neglect, 19, 1275-1282. doi:10.1016/0145-2134(95)00084-L

Gross, J. J., \& John, O. P. (2003). Individual differences in two emotion regulation processes: Implications for affect, relationships, and well-being. Journal of Personality and Social Psychology, 85, 348-362. Retrieved from: 10.1037/0022-3514.85.2.348 doi:10.1037/00223514.85.2.348

Hanson, R. F., Saunders, B. E., \& Lipovsky, J. A. (1992). The relationship between selfreported levels of distress of parents and victims in incest families. Journal of Child Sexual Abuse, 1, 49-60. doi:10.1300/J070v01n02_04

Higgins, D. (2007). Cooperation and coordination: An evaluation of the family court of Australia's magellan case-management model. Canberra, Australia: Family Court of Australia. Retrieved from https://www.researchgate.net/profile/Daryl_Higgins/publica tion/266404662_Cooperation_and_coordination_An_evaluation_of_the_Family_Court_ of_Australia's_Magellan_casemanagement_model/links/54c994210cf2f0b56c23f2b9.pdf 
Hirt, E. R, Kardes, F.R, \& Markman, K.D. (2004). Activating a mental simulation mind-set through generation of alternatives: implications for debiasing in related and unrelated domains. Journal Of Experimental Social Psychology, 40, 374-383. doi:10.1016/j. jesp.2003.07.009

Hoekstra, H. A., Ormel, J., \& De Fruyt, F. (1996). NEO personality questionnaires NEO-PI-R, NEO-FFI, manual. Lisse, The Netherlands: Swets \& Zeitlinger.

Hooper, C. A. (1992). Mothers surviving child abuse. New York, NY. Routledge.

Hunter, W. M., Coulter, M. L., Runyan, D. K., \& Everson, M. D. (1990). Determinants of placement for sexually abused children. Child Abuse \& Neglect, 14, 407-417. doi:10.1016/ 0145-2134(90)90012-I

Iacobucci, D, Posavac, S. S, Kardes, F. R, Schneider, M. J, \& Popovich, D. L. (2015). The median split: robust, refined, and revived. Journal Of Consumer Psychology, 25, 690-704. doi: 10.1016/j.jcps.2015.06.014

Keye, M. D., \& Pidgeon, A. M. (2013). Investigation of the relationship between resilience, mindfulness, and academic self-efficacy. Open Journal of Social Sciences, 1, 1-4. doi:10.4236/jss.2013.16001

Lam, J. N, \& Grossman, F. K. (1997). Resiliency and adult adaptation in women with and without self-reported histories of childhood sexual abuse. Journal Of Traumatic Stress, 10, 175-196. doi:10.1002/(ISSN)1573-6598

Leary, M. R, Tate, E. B, Adams, C. E, Batts Allen, A, \& Hancock, J. (2007). Self-compassion and reactions to unpleasant self-relevant events: the implications of treating oneself kindly. Journal Of Personality and Social Psychology, 92, 887-904. doi:10.1037/0022-3514.92.5.887

Lovibond, P. F., \& Lovibond, S. H. (1995). The structure of negative emotional states: Comparison of the Depression Anxiety Stress Scales (DASS) with the Beck depression and anxiety inventories. Behaviour Research and Therapy, 33, 335-343. doi:10.1016/00057967(94)00075-U

McKillop, N., Ronken, C., \& Vidler, S. (2011). Bravehearts Toolbox for Practitioners Working with Child Sexual Assault, The. Bravehearts Toolbox for Practitioners Working with Child Sexual Assault. Queensland, Australia: Australian Academic Press.

Neff, K. D. (2003). The development and validation of a scale to measure self-compassion. Self and Identity, 2, 223-250. doi:10.1080/15298860390209035

Neff, K. D, Kirkpatrick, K. L, \& Rude, S. S. (2007). Self-compassion and adaptive psychological functioning. Journal of Research in Personality, 41, 139-154. doi: 10.1016/j. jrp.2006.03.004

Pidgeon, A. M., Rowe, N. F., Stapleton, P., Magyar, H. B., \& Lo, B. C. (2014). Examining characteristics of resilience among university students: An international study. Open Journal of Social Sciences, 2, 14-22. doi:10.4236/jss.2014.211003

Plummer, C. A., \& Eastin, J. A. (2007). System intervention problems in child sexual abuse investigations: The mothers' perspectives. Journal of Interpersonal Violence, 22, 775-787. doi:10.1177/0886260507300753

Raffaelli, M., Andrade, F. C., Wiley, A. R., Sanchez-Armass, O., Edwards, L. L., \& AradillasGarcia, C. (2013). Stress, social support, and depression: A Test of the stress-buffering hypothesis in a mexican sample. Journal of Research on Adolescence, 23, 283-289. doi:10.1111/jora.12006

Regehr, C. (1990). Parental responses to extrafamilial child sexual assault. Child Abuse \& Neglect, 14, 113-120. doi:10.1016/0145-2134(90)90086-9

Reitsema, A. M., \& Grietens, H. (2016). Is anybody listening? The literature on the dialogical process of child sexual abuse disclosure reviewed. Trauma, Violence, \& Abuse, 17, 330-340. doi:10.1177/1524838015584368 
Rosmond, R. (2005). Role of stress in the pathogenesis of the metabolic syndrome. Psychoneuroendocrinology, 30, 1-10. doi:10.1016/j.psyneuen.2004.05.007

Rutter, M. (1987). Psychosocial resilience and protective mechanisms. American Journal of Orthopsychiatry, 57, 316-331. doi:10.1111/j.1939-0025.1987.tb03541.x10.1080/ 10538712.2013.841309

Silver, R. L, Boon, C, \& Stones, M. H. (1983). Searching for meaning in misfortune: making sense of incest. Journal Of Social Issues, 39, 81-102. doi: 10.1111/josi.1983.39.issue-2

Slade, T., Johnston, A., Oakley Browne, M. A., Andrews, G., \& Whiteford, H. (2009). 007 national survey of mental health and wellbeing: Methods and key findings. Australia and New Zealand Journal of Psychiatry., 43, 594-605. doi:10.1080/00048670902970882

Swanson, J, Valiente, C, Lemery-Chalfant, K, Bradley, R. H, \& Eggum-Wilkens, N. D. (2014). Longitudinal relations among parents' reactions to children's negative emotions, effortful control, and math achievement in early elementary school. Child Development, 85. doi: $10.1111 /$ cdev. 12260

Tabachnick, B., \& Fidell, L. (2013). Using multivariate statistics. 6th international ed. Boston, MA: Pearson.

Tedeschi, R. G, \& Calhoun, L. G. (2004). posttraumatic growth: conceptual foundations and empirical evidence. Psychological Inquiry, 15, 1-18.

Tedeschi, R. G., \& Calhoun, L. G. (2004). Posttraumatic growth: Conceptual foundations and empirical evidence. Psychological Inquiry, 15, 1-18. doi:10.1207/s15327965pli1501_01

Thomas, J. T, \& Otis, M. D. (2010). Intrapsychic correlates of professional quality of life: mindfulness, empathy, and emotional separation. Journal Of The Society for Social Work and Research, 1, 83-98. doi: 10.5243/jsswr.2010.7

Tourigny, M., Hébert, M., Daigneault, I., \& Simoneau, A. C. (2005). Efficacy of a group therapy for sexually abused adolescent girls. Journal of Child Sexual Abuse, 14, 71-93. doi:10.1300/J070v14n04_04

Turner, R. (1981). Social support as a contingency in psychological well-being. Journal of Health and Social Behavior, 22, 357-367. doi: 10.2307/2136677

Ungar, M. (2008). Resilience across cultures. The British Journal Of Social Work, 38, 218-235. doi:10.1093/bjsw/bcl343

Wei, M., Liao, K. Y. H., Ku, T. Y., \& Shaffer, P. A. (2011). Attachment, self-compassion, empathy, and subjective well-being among college students and community adults. Journal of Personality, 79, 191-221. doi:10.1111/j.1467-6494.2010.00677.x

Yancey, C. T, \& Hansen, D. J. (2010). Relationship of personal, familial, and abuse-specific factors with outcome following childhood sexual abuse. Aggression and Violent Behavior, 15, 410-421. doi: 10.1016/j.avb.2010.07.003

Zajac, K., Ralston, M. E., \& Smith, D. W. (2015). Maternal support following childhood sexual abuse: Associations with children's adjustment post-disclosure and at 9-month follow-up. Child Abuse \& Neglect, 44, 66-75. doi:10.1016/j.chiabu.2015.02.011

Zeller, M., Yuval, K., Nitzan-Assayag, Y., \& Bernstein, A. (2015). Self-compassion in recovery following potentially traumatic stress: Longitudinal study of at-risk youth. Journal of Abnormal Child Psychology, 43, 645-653. doi:10.1007/s10802-014-9937-y

Zoellner, T., \& Maercker, A. (2006). Posttraumatic growth in clinical psychology-A critical review and introduction of a two component model. Clinical Psychology Review, 26, 626653. doi:10.1016/j.cpr.2006.01.008 